\title{
Use of Diuretics is Associated with Higher Risk of Sarcopenia in Older Adults with Hypertension
}

Francisco de Assis Dias Martins Junior, ${ }^{1}$ (i) Dahany Pamela Acta Mateo, ${ }^{10}$ Fábio Junior de Miranda Silva, ${ }^{10}$ Samara Silva de Moura, ${ }^{1 \oplus}$ Emerson Cruz Oliveira, ${ }^{\circledR}$ Daniel Barbosa Coelho, ${ }^{1 \oplus}$ Eduardo Bearzoti, ${ }^{\circledR}$ Kelerson Mauro de Castro Pinto, ${ }^{1[}$ Lenice Kappes Becker ${ }^{1}{ }^{\circledR}$

School of Physical Education of Federal University of Ouro Preto, ${ }^{\prime}$ Ouro Preto, MG - Brazil

Department of Statistic/ICEB-DEEST, Federal University of Ouro Preto, ${ }^{2}$ Ouro Preto, MG - Brazil

\section{Abstract}

Background: Sarcopenia is a disease that involves skeletal muscle mass loss and is highly prevalent in the older adult population. Moreover, the incidence of sarcopenia is increased in patients with hypertension.

Objective: The study aimed to evaluate the association between the classes of the drugs used for arterial hypertension treatment and the presence or absence of sarcopenia.

Methods: 129 older adults with hypertension were evaluated by the researchers who registered the participants medication for arterial hypertension treatment. Sarcopenia level was measured by anthropometric parameters, muscular strength, and functional capacity. The data were analyzed by one-way ANOVA followed by post-hoc test and Fisher's exact test; statistical significance was set at 0.05 .

Results: Age was not different between women with different levels of sarcopenia, but significant differences were

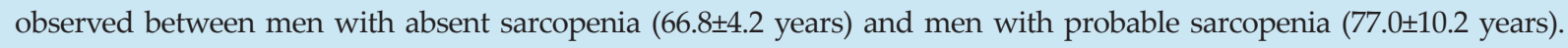
Individuals with absent sarcopenia showed higher handgrip strength (men: $33.8 \pm 7.4$, women: $23.2 \pm 4.6 \mathrm{Kgf}$ ) in comparison with those with sarcopenia (men with probable sarcopenia: $9.5 \pm 3.3 \mathrm{Kgf}$, women with probable, confirmed, and severe sarcopenia: $11.7 \pm 2.5,12.2 \pm 3.0,11.8 \pm 1.8 \mathrm{Kgf}$, respectively). The analysis showed an association between the type of medication and degree of sarcopenia; diuretics were significantly associated with probable sarcopenia, and angiotensin II receptor blockers (alone or in combination with diuretics) was associated with absence of sarcopenia.

Conclusions: In conclusion, handgrip strength was a good method to diagnose sarcopenia, and diuretics were associated with increased risk of sarcopenia in older adults with hypertension.

Keywords: Hypertension; Diuretics/therapeutic use; Sarcopenia/complications; Aging; Angiotensin Receptor Blockers.

\section{Introduction}

Sarcopenia is defined as a progressive and generalized loss of skeletal muscle mass and function (i.e., muscle power, muscle strength, and physical performance). ${ }^{1-5}$ Since 2016, it has been recognized as a disease. ${ }^{6}$ People aged 50 years and older lose $1 \%$ of skeletal muscle mass, $2 \%$ of gait speed, and 1.9 to $5.0 \%$ of handgrip strength per year, ${ }^{7,8}$ and these variables have been used for the assessment of sarcopenia by renowned organizations. ${ }^{9}$ However, the cause and pathogenesis of sarcopenia are not fully understood; the target in sarcopenia treatment is to improve patient survival and quality of life.

Sarcopenia is highly prevalent in older adults, ${ }^{10}$ and the incidence of arterial hypertension is over $70 \%$ in this population. Data from population studies have shown that the prevalence of hypertension is increased in patients with sarcopenia. ${ }^{11}$

Hypertension pharmacotherapy usually consists of single therapy or a combination of different medications. 
The most used medication classes are angiotensin II receptor blockers (ARBs), angiotensin-converting enzyme inhibitors (ACEIs), diuretics (DIUs), calcium channel blockers, and beta-blockers. ${ }^{12}$

Several researchers have investigated the contribution of different medications to the treatment of sarcopenia, including the role of the renin angiotensin system in skeletal muscle and functional capacity. ${ }^{13}$ The reninangiotensin system modulates muscle function, and ARBs and ACEIs have been shown to remodel the skeletal muscle, protecting against atrophy by transforming growth factor beta. ${ }^{14}$ ACEIs have been used to improve skeletal muscle function, as they increase endothelial function, promote angiogenesis, and have anti-inflammatory effects that increase mitochondrial content and insulin-like growth factor values. ${ }^{15-17}$

Meanwhile, the chronic use of loop DIUs, one of the classes of medication used in the treatment of hypertension, has been shown to potentially cause loss of muscle function by suppressing the sodium-potassium pump. In patients with renal failure, ${ }^{18}$ heart failure, and hypertension, treatment with DIUs impairs the sodiumpotassium pump function. Muscle biopsy specimens of patients have shown decreased intracellular potassium and increased intracellular sodium concentration. ${ }^{19}$

The present study aimed to evaluate the possible associations between drugs used for hypertension and the presence or absence of sarcopenia in the older adult. Handgrip strength, skeletal muscle mass, and physical performance measure were used to determine the level of sarcopenia, following the European Working Group on Sarcopenia in older people criteria. ${ }^{20}$

\section{Material and methods}

\section{Study design and participants}

This cross-sectional study was conducted from June 2018 to April 2019 in three public geriatric healthcare centers in the cities of Ouro Preto and Mariana, Brazil. The sample was 129 older adults of both sexes, who were recruited by convenience. The sample size was calculated for an $80 \%$ confidence interval, using a sample size of 15,000 (prevalence of older adults in the two cities evaluated), anticipated frequency of $70 \%$ and test power of $5 \%$.

Inclusion criteria were patients older than 60 years taking anti-hypertensive drugs, capable of walking without assistance, with no history of injury in the lower limbs in the last six months. Patients taking beta-blockers and those with comorbidities other than hypertension were excluded from the study. The study was approved by the ethics committee of the Federal University of Ouro Preto (approval number 82376117.3.0000.5150). All participants signed an informed consent form and received information regarding participation in the study.

\section{Collection of clinical data}

For assessment of the drugs used for the treatment of hypertension and other comorbidities, we developed a standard questionnaire with the following information: name of the medication used, and dosage (dose/frequency/ time) prescribed. Patients were stratified by classes of antihypertensive drugs.

\section{Anthropometric measurements}

The following anthropometric measurements were assessed - body mass $(\mathrm{Kg})$, height ( $\mathrm{H}$; in meter), body mass index (body mass $[\mathrm{Kg}] /$ height squared $\left[\mathrm{m}^{2}\right]$, and percentage of body fat and muscle mass. Body fat was estimated using the tetrapolar bioelectrical impedance method (Biodynamics TBW 310); four electrodes were used: two electrodes (with red clips) placed on the posterior surface of the hand (one on middle finger and the other slightly above the wrist joint) and two (with black clips) placed on the posterior surface of the foot (one at the base of the middle finger and the other slightly above the ankle joint line between the malleoli) on the right side of the participant. . $^{21,22}$ Skeletal muscle mass (SMM) was estimated using the formula proposed by Janssen et al., ${ }^{23}$ using $\mathrm{H}$ (in centimeters), bioimpedance resistance $(\mathrm{R}$; in ohm $)$, sex $(0=$ women; $1=$ men $)$, and age parameters: $\mathrm{SMM}=\left[\left(\mathrm{H}^{2} / \mathrm{R} \times 0.401\right)+(\operatorname{sex} \times 3.825)+(\right.$ age $x$ $0.071)]+5.102$.

\section{Handgrip strength}

Handgrip strength was measured using an analog handheld dynamometer (Jamar®) to measure handgrip strength. ${ }^{22}$ Each participant was seated on a standard armless chair in an uptight trunk position with a $90^{\circ}$ knee angulation, neutrally rotating abduction shoulder, $90^{\circ} \mathrm{elbow}$ flexion, slight forearm pronation, and neutral wrist. At the evaluator's cue, each participant applied their maximum strength to the device with the dominant hand; motivational verbal commands were used to optimize the test. ${ }^{22}$ The test was performed three times with five seconds of duration for each attempt and one minute of rest between attempts to avoid muscle fatigue during the test. 


\section{Physical performance}

The four-meter walking test was used to assess physical performance. Each participant was asked to walk six meters on a flat straight course at the fastest speed possible, and the time required to walk the central four meters was measured. ${ }^{24}$ The highest speed among three measurements was used in the analyses; the cutoff adopted was $<0.8 \mathrm{~m} / \mathrm{s}$ for both sexes, as proposed by the European Consensus. ${ }^{9}$

\section{Diagnosis of sarcopenia}

The diagnosis of sarcopenia and analysis of the degree of sarcopenia were made based on the European Working Group on sarcopenia in older people criteria, ${ }^{20}$ which requires the measurement of a combination of muscle mass, muscle strength, and physical performance. Diagnosis started with the measurement of muscle strength (handgrip strength test), with a cut-off point of 27 kilogram-force (Kgf) for men and $16 \mathrm{Kgf}$ for women; results lower than these values indicated probable sarcopenia. The second step was the measurement of muscle mass, with cutoffs of $8.5 \mathrm{~kg} / \mathrm{m}^{2}$ for men and 5.75 $\mathrm{kg} / \mathrm{m}^{2}$ for women. ${ }^{25}$ Participants with low muscle strength and muscle masses below these values had the diagnosis of sarcopenia confirmed. The third step was the measurement of physical performance through gait speed, values below the cut-off of $0.8 \mathrm{~m} / \mathrm{s}$ indicated severe sarcopenia. Then patients were classified into four categories: absent, probable sarcopenia, sarcopenia, and severe sarcopenia.

\section{Statistical analysis}

Continuous variables were described as mean and standard deviation, and categorical variables as absolute and relative frequencies. Comparisons of continuous variables (age, muscle mass index, handgrip strength, and gait speed), were assessed using GraphPad Prism (Version 6.0). First, data normality was verified by the Kolmogorov-Smirnov test. Subsequently, one-way ANOVA was performed, followed by Tukey's post hoc test. Statistical significance was set at $\mathrm{p}<0.05$.

The categorical variables: type of medication and degree of sarcopenia were displayed in a contingency table, and Fisher's exact test ${ }^{26}$ was performed to verify whether these variables were associated. Subsequently, the correspondence analysis (a multivariate technique) ${ }^{27}$ was used to elucidate the nature of this association, particularly to identify which combinations of variables that contributed most to the association. Correspondence analysis was performed with the "FactoMineR" package ${ }^{28}$ of R language.

\section{Results}

Table 1 shows characteristics of participants and medications used to treat hypertension. Most patients used ARBs + DIUs ( $\mathrm{n}=119 ; 70,4 \%)$, followed by calcium blockers $(n=22 ; 13.0 \%)$, ACEIs $(n=14 ; 8,3 \%)$, and beta-blockers $(n=13$; $7,7 \%$ ). Table 1 also lists the number of classes of medication used by the patients.

Figure 1 shows the mean number of patients according to the level of sarcopenia (absent; probable; confirmed; and severe) and age (a), handgrip strength (b), muscle mass index (c), and gait speed (d). The results revealed a difference between men's age in the "probable sarcopenia" group compared with "absent" group, and none of the men showed confirmed or severe levels of sarcopenia. Individuals with sarcopenia reported lower handgrip strength, and those with severe sarcopenia had lower muscle mass index and lower gait speed.

Regarding the drugs used to treat hypertension, only seven individuals did not use ARBs or DIUs. In addition, of the 31 individuals who were diagnosed with sarcopenia, 25 used ARBs, DIUs, or a combination thereof. We chose to study the association between sarcopenia and the drugs used for hypertension treatment in the 53 individuals who used only ARBs ( $n=17)$, DIUs $(n=13)$, or the combination of ARBs + DIUs $(n=23)$. Distribution of these combinations is illustrated in Figure 2.

The variables "type of medication" and "degree of sarcopenia" were then displayed in a two-way contingency table (Table 2). The Fisher's exact test indicated that these two categorical variables were associated ( $p$-value: 0.0466 ). As such, correspondence analysis was carried out to investigate the nature of this association. This multivariate technique decomposes the chi-squared statistic associated with a contingency table into orthogonal factors, ordered by degree of variation in the data set. For instance, if the first two factors accounted for most (say, 70\%) of the variation, a simple scatter plot of these factors should be sufficient for identifying the categories of variables that most contributed to the association. The scatter plot of the variables "type of medication" and "degree of sarcopenia" is shown in Figure 3a. Two groups of categories contributed most to the association: DIUs associated with probable sarcopenia, and absence of sarcopenia associated with ARBs and ARBs + DIUs. However, as the first two factors accounted for only $52 \%$ of the variation in the contingency table, we chose to consider a third factor, to confirm if this trend would continue. The first three factors explained $72 \%$ of the variation and were then 


\begin{tabular}{|c|c|c|c|c|c|c|c|c|c|c|}
\hline & & \multicolumn{5}{|c|}{ Classes of medication } & \multicolumn{4}{|c|}{ Number of drug classes } \\
\hline & & ARB & DIU & $\begin{array}{l}\text { calcium } \\
\text { blocker }\end{array}$ & ACEI & $\beta$-blocker & 1 & 2 & 3 & 4 \\
\hline \multirow{3}{*}{$\mathrm{n}$} & Women & 52 & 53 & 19 & 11 & 11 & 27 & 43 & 18 & 0 \\
\hline & Men & 8 & 6 & 3 & 3 & 2 & 8 & 4 & 1 & 1 \\
\hline & Total & 60 & 59 & 22 & 14 & 13 & 35 & 47 & 19 & 1 \\
\hline \multirow{3}{*}{$\begin{array}{l}\text { Age } \\
\text { (years) }\end{array}$} & Women & $69.4 \pm 7.0$ & $70.4 \pm 7.2$ & $69.3 \pm 6.9$ & $68.8 \pm 5.8$ & $70.9 \pm 7.8$ & $69.3 \pm 6.5$ & $69.1 \pm 6.6$ & $70.5 \pm 7.8$ & $\mathrm{n} / \mathrm{a}$ \\
\hline & Men & $66.0 \pm 4.5$ & $69.5 \pm 3.0$ & $68.7 \pm 1.5$ & $69.7 \pm 1.5$ & $69.0 \pm 1.4$ & $67.3 \pm 5.3$ & $67.3 \pm 6.3$ & 71 & 70 \\
\hline & Total & $68.9 \pm 6.8$ & $70.3 \pm 6.9$ & $69.2 \pm 6.4$ & $69.0 \pm 5.2$ & $70.6 \pm 7.1$ & $68.9 \pm 6.3$ & $68.9 \pm 6.3$ & $70.5 \pm 7.6$ & 70 \\
\hline \multirow{3}{*}{$\begin{array}{l}\text { BMI } \\
\left(\mathrm{kg} / \mathrm{m}^{2}\right)\end{array}$} & Women & $28.4 \pm 5.2$ & $28.4 \pm 4.7$ & $28.0 \pm 4.9$ & $26.9 \pm 4.5$ & $29.5 \pm 6.1$ & $28.4 \pm 4.7$ & $28.7 \pm 5.2$ & $27.6 \pm 5.3$ & $\mathrm{n} / \mathrm{a}$ \\
\hline & Men & $26.8 \pm 6.0$ & $30.1 \pm 4.4$ & $32.8 \pm 6.0$ & $31.1 \pm 7.2$ & $31.4 \pm 10.1$ & $26.1 \pm 5.5$ & $28.3 \pm 3.9$ & 30.4 & 38.6 \\
\hline & Total & $28.2 \pm 5.3$ & $28.2 \pm 5.0$ & $28.7 \pm 5.2$ & $27.8 \pm 5.2$ & $29.8 \pm 6.3$ & $27.2 \pm 4.8$ & $28.7 \pm 4.8$ & $27.8 \pm 5.2$ & 38.6 \\
\hline \multirow{3}{*}{$\begin{array}{l}\% \text { of } \\
\text { users }\end{array}$} & Women(n=107) & 48.60 & 49.53 & 17.76 & 10.28 & 10.28 & 25.23 & 40.19 & 16.82 & 0.00 \\
\hline & Men (n=22) & 36.36 & 27.27 & 13.64 & 13.64 & 9.09 & 36.36 & 18.18 & 4.55 & 4.55 \\
\hline & Total $(\mathrm{n}=129)$ & 46.51 & 45.74 & 17.05 & 10.85 & 10.08 & 27.13 & 36.43 & 14.3 & 0.78 \\
\hline
\end{tabular}

used to calculate Euclidean distances between categories. Subsequently, the Ward's clustering method ${ }^{27}$ was applied to the categories. The resulting dendrogram is shown in Figure 3b. Again, it suggested that DIUs were associated with probable sarcopenia, whereas absent sarcopenia was associated with ARBs or ARBs + DIUs.

\section{Discussion}

Sarcopenia is a disease (ICD-10- M62.84) that affects over 10,000 older adults worldwide, and $43 \%$ of those aged 80 or above. Recently, sarcopenia has become the focus of intensive studies, and progress has been made toward a better understanding of its etiology and associated causes. Considering the consequences of sarcopenia and the aging of the world's population, research should continue to refine strategies for diagnosis and prevention of sarcopenia in hypertensive older adults. Falls, functional decline, and fragility are known to cause adverse health effects in the elderly population. ${ }^{9}$ Only $5.3 \%$ of frail persons are not sarcopenic. Several strategies must be adopted to minimize this problem, and one of them is to identify possible drugs involved in this process. ${ }^{29}$

Taking into account the aging of the Brazilian population ${ }^{30}$ - the focus of the present study - researchers should consider building a consensus regarding the diagnosis of sarcopenia in Brazil. There are guidelines on sarcopenia for the Brazilian population; the present study was based on the European Consensus ${ }^{20}$ and the SMM index proposed by Janssen et al..$^{25}$

In our study population, although age range was not different between women with different levels of 
a)

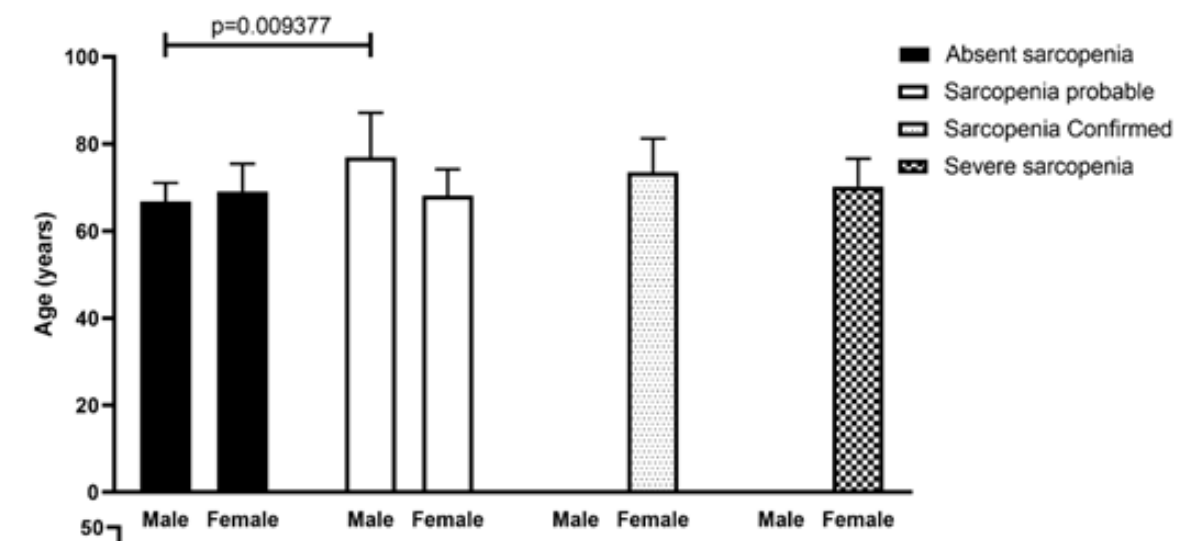

b)

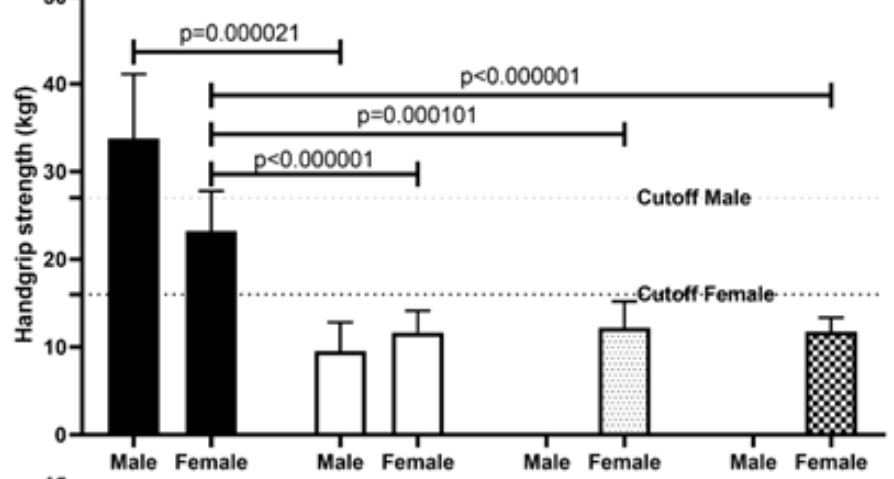

c)

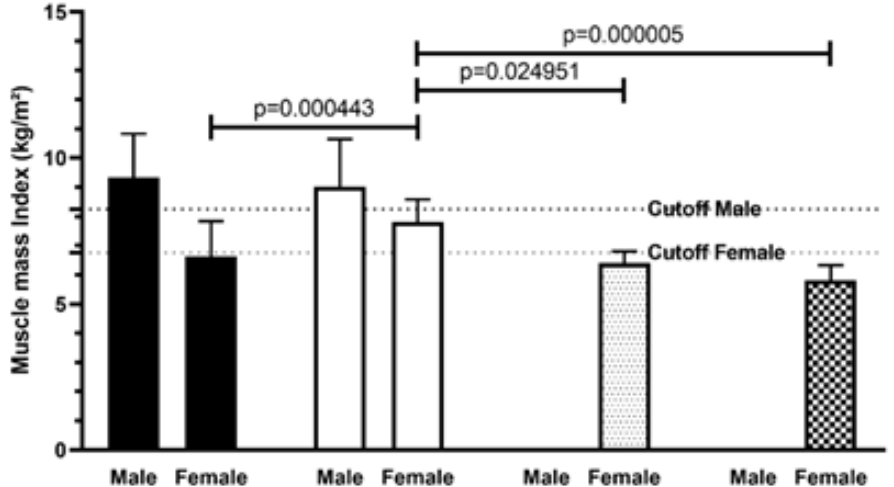

d)

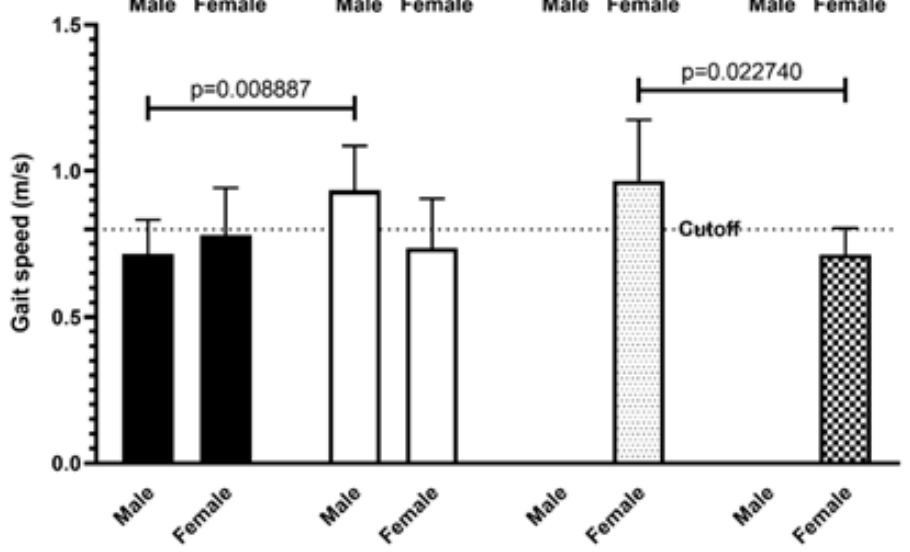
mass index (C) and gait speed (D); Multiple $t$ tests; data expressed as mean \pm standard deviation. Kgf: kilogram-force; $\mathrm{kg} / \mathrm{m}^{2}$ : kilogram per square meter; $\mathrm{m} / \mathrm{s}$ : meter per second 


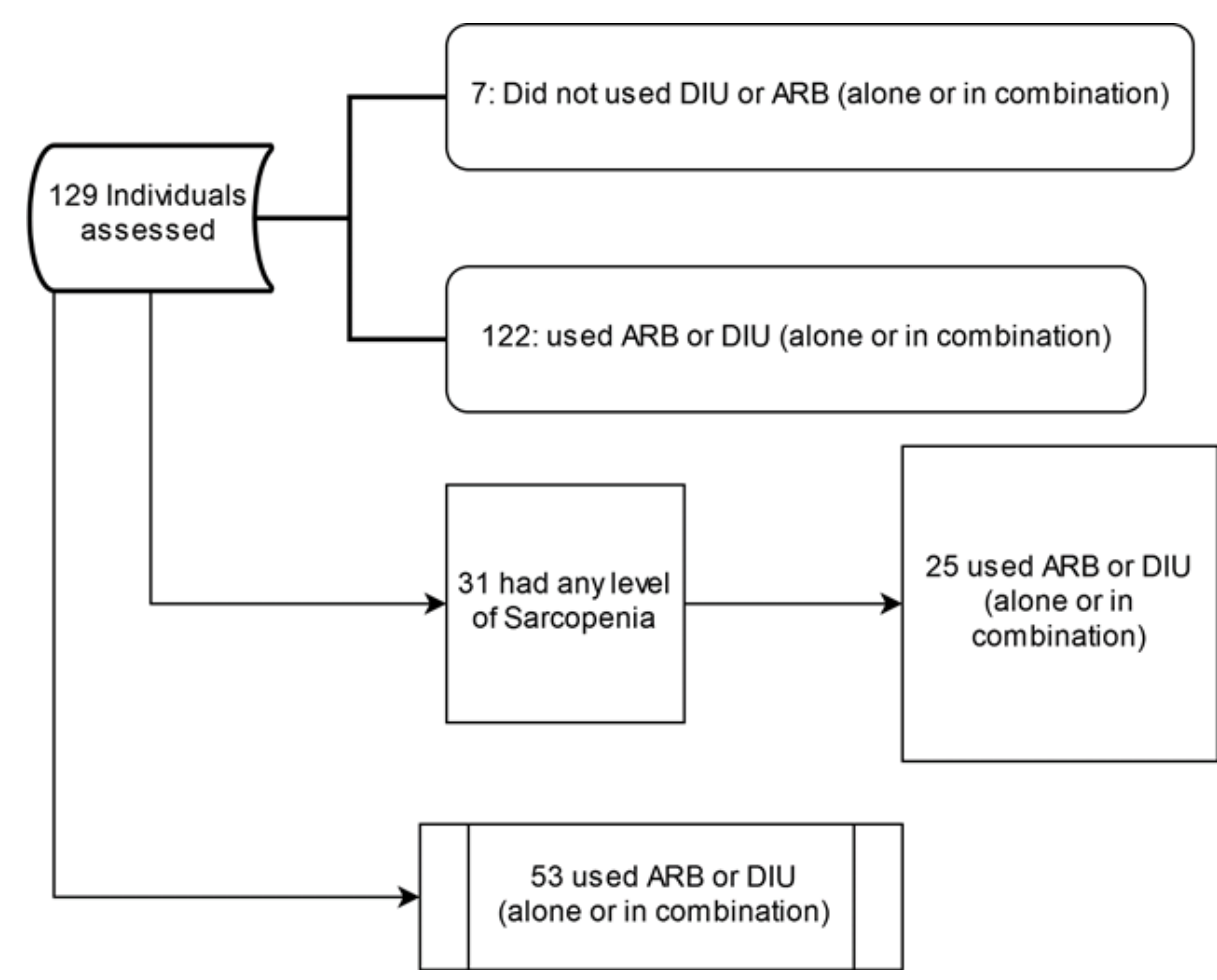

Figure 2 - Study design

Table 2 - Number of individuals distributed by sarcopenia level

\begin{tabular}{lllll}
\hline & ARB & DIU & ARB+DIU & Total individuals \\
Absent sarcopenia & 11 & 7 & 20 & 38 \\
\hline Probable & 5 & 6 & 1 & 12 \\
\hline Sarcopenia confirmed & 0 & 0 & 0 & 2 \\
\hline Severe sarcopenia & 1 & 0 & 1 \\
\hline ARB: Angiotensin II receptor blocker; DIU: Diuretics; $p$-value for Fisher's Exact Test: 0.04662 & \\
\hline
\end{tabular}

sarcopenia, mean age was significantly different between men with absent and probable sarcopenia. The prevalence of sarcopenia in older adults aged between 60 and 70 years varies from $5 \%$ to $13 \%$, and in those aged 80 years and older, from $11 \%$ to $50 \%$, according to SMM. ${ }^{31}$

Meanwhile, mean values of the handgrip test, muscle mass, and gait speed results confirmed that handgrip strength is a good parameter for classifying sarcopenia. Studies have used the handgrip strength test for diagnosing sarcopenia, ${ }^{2,5,9}$ and showed it has good intraand inter-observer reliability and can be used in clinical practice. ${ }^{32,33}$ Our data revealed that muscle mass index and gait speed seemed to act as confounding factors, as the absent and probable sarcopenia groups showed different values. Thus, both parameters may be best used after a first screening with handgrip strength.

Coelho-Junior et al., ${ }^{34}$ also reported an increased prevalence of hypertension in individuals with sarcopenia. In our study, most patients (122 out of 129) used ARBs or DIUs. A possible contributing factor to this that these medications are provided for free by the public health services in Brazil. 
a)

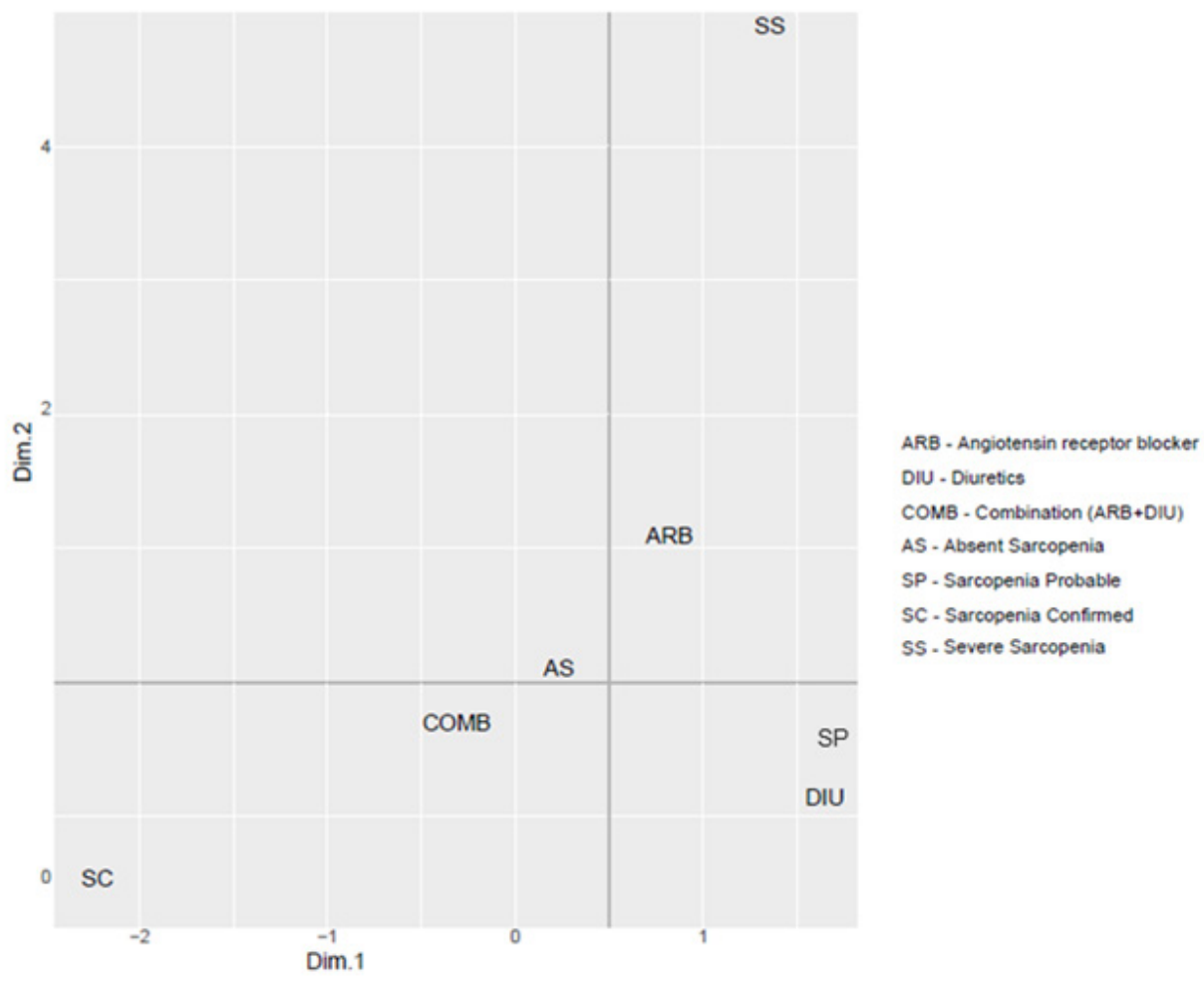

b)

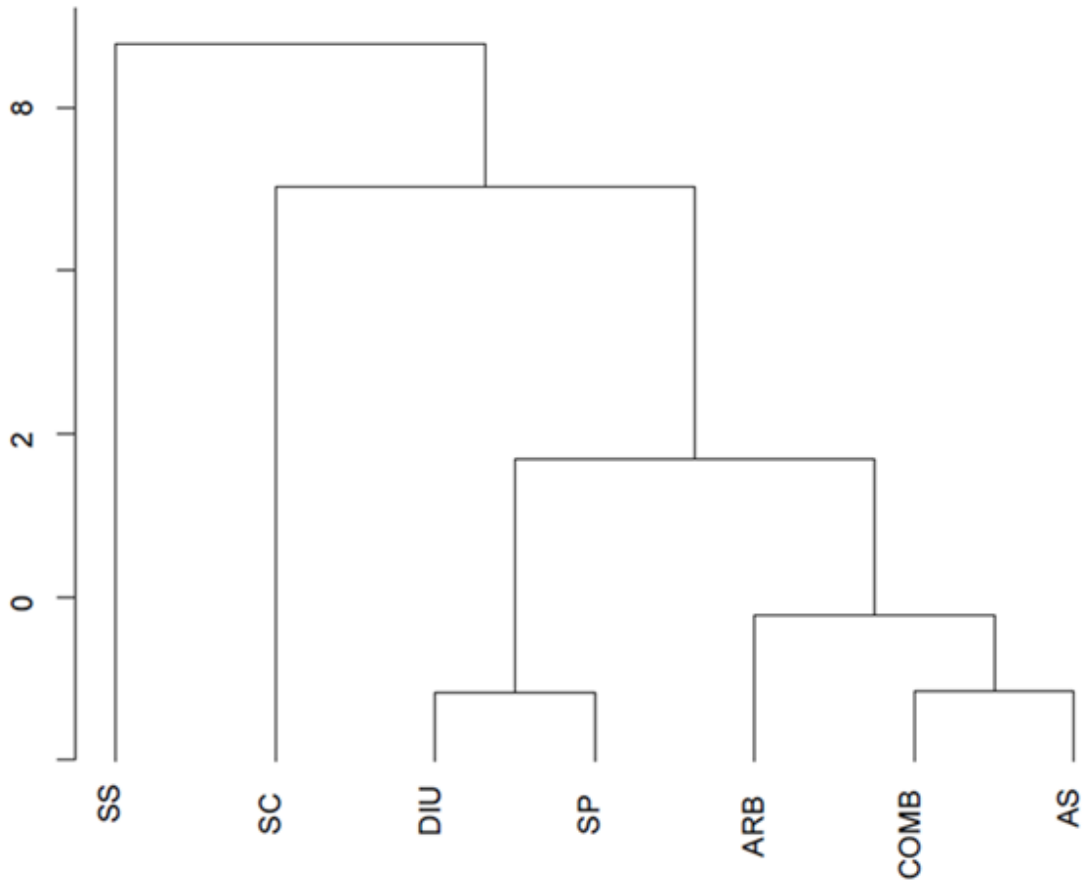

Figure 3 - a: Scatter plot of the first two orthogonal factors of the correspondence analysis of the variables: medications (DIU: diuretics; ARB: angiotensin-receptor blocker; combination: DIU+ARB) and level of sarcopenia (AS: absent sarcopenia; PS: probable sarcopenia; CS: confirmed sarcopenia; SS: severe sarcopenia). b: Dendrogram of cluster analysis with the first three factors of the correspondence analysis of the variables: medications (DIU; ARB; combination: DIU+ARB) and levels of sarcopenia (AS; PS; CS; SS) 
The scatter plot showed the association between the type of medication and degree of sarcopenia, and two associations seemed to contribute most to this, the association between DIUs and probable sarcopenia, and the association between absence of sarcopenia and ARBs and ARBs + DIUs. This result was confirmed by the Ward's clustering algorithm.

Treatment with ARBs can have protective effects against muscle loss, since angiotensin II increases superoxide production, ${ }^{35}$ reduces the autocrine insulin-like growth factor-1 signaling, ${ }^{36}$ decreases mitochondrial function, ${ }^{35}$ and increases apoptosis ${ }^{37}$ in skeletal muscles, leading to muscle loss. In humans (cardiovascular patients) and in a rat model for heart failure associated with muscle atrophy and with increase in fatigability, ARBs provided protective effects by reversing most of the molecular markers of skeletal muscle loss. ${ }^{38}$ Brown et al., ${ }^{39}$ reported that the use of ARBs instead of ACEIs for the treatment of hypertension could prevent mobility disability in older adults, especially in those at risk for decreased mobility and loss of physical independence. Further studies are necessary to investigate if the molecular and biochemical effects are reflected in worse physical performance and reduction in muscle mass.

Regarding the use of DIUs, the present study showed a significant association between DIUs and sarcopenia. A study ${ }^{40}$ has shown that in patients with renal failure, heart failure, and hypertension, treatment with DIUs impaired the sodium-potassium pump function. Indeed, muscle biopsy specimens of patients demonstrated a reduction in intracellular potassium concentration and increase in intracellular sodium. ${ }^{19}$ In vitro studies using skeletal muscle cells have shown that loop DIUs block the $\mathrm{Na}+-\mathrm{K}+-2 \mathrm{Cl}-$ cotransporter activity, thereby suppressing skeletal muscle differentiation. ${ }^{18}$ Hanai et al., ${ }^{41}$ also reported that the use of a higher dose of loop DIUs was associated with a faster decrease in SMM in patients with liver cirrhosis, independent of the severity of liver disease, suggesting that loop DIUs are one of the risk factors of sarcopenia.

Our study has some limitations that need to be considered. First, there was a small number of individuals that used only DIUs. Second, the frequency and time of use of drugs were not evaluated with respect to sarcopenia level. Third, the diagnosis of sarcopenia was made based on the European Consensus. It is necessary to confirm the reproducibility of this consensus in the Brazilian population.

\section{Conclusion}

In conclusion, age of elderly women with sarcopenia was not different from that of elderly women without sarcopenia. The handgrip strength test was a good method for diagnosing sarcopenia. The use of DIUs was associated with increased risk of sarcopenia in hypertensive older adults. Results of the present study is a starting point for health professionals to carefully consider antihypertensive prescription to elderly patients.

\section{Author contributions}

Conception and design of the research: Becker L. Acquisition of data: Mateo D. Analysis and interpretation of the data: Martins Júnior F. Statistical analysis: Martins Júnior F; Pinto K; Bearzoti E. Obtaining financing: Becker L; Coelho D. Writing of the manuscript: Martins Júnior F. Critical revision of the manuscript for intellectual content: Oliveira E; Becker L.

\section{Potential Conflict of Interest}

No potential conflict of interest relevant to this article was reported.

\section{Sources of Funding}

This study was partially funded by Coordination for the Improvement of Higher Education Personnel (CAPES) of Brazil (Finance Code 001), by the ProRectory of Research and Postgraduate studies of the Federal University of Ouro Preto (PROPP-UFOP) and Fapemig APQ-02357-15.

\section{Study Association}

This article is part of the thesis of master submitted by Lenice Kappes Becker, from Universidade Federal de Ouro Preto.

\section{Ethics approval and consent to participate}

This study was approved by the Ethics Committee of the Federal University of Ouro Preto under the protocol number 82376117.3.0000.5150. All the procedures in this study were in accordance with the 1975 Helsinki Declaration, updated in 2013. Informed consent was obtained from all participants included in the study. 


\section{References}

1. Chen LK, Liu LK, Woo J, Assantachai P, Auyeung TW, Bahyah KS, et al. Sarcopenia in Asia: consensus report of the Asian Working Group for Sarcopenia. Am Med Dir Assoc. 2014;15(2):95-101. doi: 10.1016/j. jamda.2013.11.025.

2. Cruz-Jentoft AJ, Baeyens JP, Bauer JM, Boirie Y, Cederholm T, Landi F, et al. Sarcopenia: European consensus on definition and diagnosis Report of the European Working Group on Sarcopenia in Older People. Age Ageing. 2010;39(4):412-23. doi: 10.1093/ageing/afq034.

3. Fielding RA, Vellas B, Evans WJ, Bhasin S, Morley JE, Newman AB, et al. Sarcopenia: an undiagnosed condition in older adults. Current consensus definition: prevalence, etiology, and consequences. International working group on sarcopenia. Am Med Dir Assoc. 2011;12(4):249-56. doi: 10.1016/j.jamda.2011.01.003.

4. Muscaritoli M, Anker S, Argiles J, Aversa Z, Bauer J, Biolo G, et al. Consensus definition of sarcopenia, cachexia and pre-cachexia: joint document elaborated by Special Interest Groups (SIG)“cachexiaanorexia in chronic wasting diseases" and "nutrition in geriatrics". Clin Nutr. 2010;29(2):154-9. doi: 10.1016/j.clnu.2009.12.004.

5. Cruz-Jentoft AJ, Bahat G, Bauer J, Boirie Y, Bruyère O, Cederholm T, et al. Sarcopenia: revised European consensus on definition and diagnosis. Age Ageing. 2018;48(1):16-31. DOI: 10.1093/ageing/afy169

6. Anker SD, Morley JE, von Haehling S. Welcome to the ICD-10 code for sarcopenia. Cachexia Sarcopenia Muscle. 2016;7(5):512-4.

7. Goodpaster BH, Park SW, Harris TB, Kritchevsky SB, Nevitt M, Schwartz AV, et al. The loss of skeletal muscle strength, mass, and quality in older adults: the health, aging and body composition study. Gerontol A Biol Sci Med Sci. 2006;61(10):1059-64.

8. Auyeung TW, Lee SWJ, Leung J, Kwok T, Woo J. Age-associated decline of muscle mass, grip strength and gait speed: A 4-year longitudinal study of 3018 community-dwelling older C hinese. Geriatrics gerontology international. 2014;14:76-84.

9. Cruz-Jentoft AJ, Sayer AA. Sarcopenia. Lancet. 2019;393(10191):2636-46. doi: 10.1016/S0140-6736(19)31138-9.

10. Iolascon G, Di Pietro G, Gimigliano F, Mauro GL, Moretti A, Giamattei MT, et al. Physical exercise and sarcopenia in older people: position paper of the Italian Society of Orthopaedics and Medicine (OrtoMed). Clin Cases Miner Bone Metab. 2014;11(3):215-21. PMID: 25568656

11. Coelho-Junior HJ, Gambassi BB, Irigoyen MC, Goncalves IO, Oliveira PLL, Schwingel PA, et al. Hypertension, Sarcopenia, and Global Cognitive Function in Community-Dwelling Older Women: A Preliminary Study. J Aging Res. 2018;2018:9758040. doi: 10.1155/2018/9758040.

12. Bea JW, Wassertheil-Smoller S, Wertheim BC, Klimentidis Y, Chen Z, Zaslavsky O, et al. Associations between ACE-Inhibitors, Angiotensin Receptor Blockers, and Lean Body Mass in Community Dwelling Older Women. J Aging Res. 2018;2018. doi: 10.1155/2018/8491092

13. Sartiani L, Spinelli V, Laurino A, Blescia S, Raimondi L, Cerbai E, et al. Pharmacological perspectives in sarcopenia: a potential role for renin-angiotensin system blockers? Clin Cases Miner Bone Metab. 2015;12(2):135-8. doi: 10.11138/ccmbm/2015.12.2.135.

14. Campins L, Camps M, Riera A, Pleguezuelos E, Yebenes JC, Serra-Prat M. Oral Drugs Related with Muscle Wasting and Sarcopenia. A Review. Pharmacology. 2017;99(1-2):1-8. doi: 10.1159/000448247.

15. Fabre JE, Rivard A, Magner M, Silver M, Isner JM. Tissue inhibition of angiotensin-converting enzyme activity stimulates angiogenesis in vivo. Circulation. 1999;99(23):3043-9. doi: 10.1161/01.cir.99.23.3043.

16. de Cavanagh EM, Piotrkowski B, Basso N, Stella I, Inserra F, Ferder L, et al. Enalapril and losartan attenuate mitochondrial dysfunction in aged rats. FASEB J. 2003;17(9):1096-8. doi: 10.1096/fj.02-0063fje

17. Maggio M, Ceda GP, Lauretani F, Pahor M, Bandinelli S, Najjar SS, et al. Relation of angiotensin-converting enzyme inhibitor treatment to insulin-like growth factor- 1 serum levels in subjects $>65$ years of age (the InCHIANTI study). Am J Cardiol. 2006;97(10):1525-9. doi: 10.1136/ bmj.296.6620.455.

18. Mandai S, Furukawa S, Kodaka M, Hata Y, Mori T, Nomura N, et al Loop diuretics affect skeletal myoblast differentiation and exerciseinduced muscle hypertrophy. Sci Rep. 2017;7:46369. doi: 10.1038/ srep46369.

19. Dorup I, Skajaa K, Clausen T, Kjeldsen K. Reduced concentrations of potassium, magnesium, and sodium-potassium pumps in human skeletal muscle during treatment with diuretics. Br Med J (Clin Res Ed). 1988;296(6620):455-8. doi: 10.1136/bmj.296.6620.455.

20. Cruz-Jentoft AJ, Bahat G, Bauer J, Boirie $Y$, Bruyère $O$, Cederholm T, et al. Writing Group for the European Working Group on Sarcopenia in Older People 2 (EWGSOP2), and the Extended Group for EWGSOP2. Sarcopenia: revised European consensus on definition and diagnosis. Age Ageing. 2019;48(1):16-31. doi: 10.1093/ageing/afy169.

21. Khalil SF, Mohktar MS, Ibrahim F. The theory and fundamentals of bioimpedance analysis in clinical status monitoring and diagnosis of diseases. Sensors (Basel). 2014;14(6):10895-928. DOI: 10.3390/ s140610895

22. Dias JA, Ovando AC, Külkamp W, Borges Junior NG. Hand grip strength: evaluation methods and factors influencing this measure. Revista Brasileira de Cineantropometria Desempenho Humano 2010;12(3):209-16.

23. Janssen I, Heymsfield SB, Baumgartner RN, Ross R. Estimation of skeletal muscle mass by bioelectrical impedance analysis. J Appl Physiol (1985). 2000;89(2):465-71. doi: 10.1152/jappl.2000.89.2.465.

24. Novaes RD, Miranda AS, Dourado VZ. Usual gait speed assessment in middle-aged and elderly Brazilian subjects. Rev Bras Fisioterapia. 2011;15(2):117-22

25. Janssen I, Baumgartner RN, Ross R, Rosenberg IH, Roubenoff R Skeletal muscle cutpoints associated with elevated physical disability risk in older men and women. Am J Epidemiol. 2004;159(4):413-21. DOI: 10.1152/jappl.2000.89.2.465

26. Agresti A. Logit models for multinomial responses. Categorical data analysis.USA: Wiley;2002. Book Series Wiley Series in Probability and Statistics. Doi; :org/10.1002/047-1249688.ch7

27. Johnson RAW, Dean W. Applied multivariate statistical analysis. 6th New Jersey US: Pearson Prentice Hall; 2007.

28. Lê S, Josse J, Husson F. FactoMineR: an R package for multivariate analysis. Journal of statistical software. 2008;25(1):1-18. DOI:10.18637/ jss.v025.i01

29. Sanford AM, Morley JE, Berg-Weger M, Lundy J,Little MO, Leonard $\mathrm{K}$, et al. "High prevalence of geriatric syndromes in older adults." Plos One 15.6 (2020): e0233857. doi: 10.1371/journal.pone.0233857.

30. Neumann LTV, Albert S. Aging in Brazil. The Gerontologist. 2018;58(4):611-7.

31. da Silva AT de Oliveira Duarte Y, Santos JF, Wong R, Lebrão M. Prevalence and associated factors of sarcopenia among elderly in Brazil: findings from the SABE study. J Nutr Health Aging. 2014;18(3):284-90. doi: 10.1007/s12603-013-0413-0.

32. Bohannon RW, Schaubert KL. Test-retest reliability of grip-strength measures obtained over a 12-week interval from community-dwelling elders. J Hand Ther. 2005;18(4):426-8. doi: 10.1197/j.jht.2005.07.003.

33. Peolsson A, Hedlund R, Oberg B. Intra- and inter-tester reliability and reference values for hand strength. J Rehabil Med. 2001;33(1):36-41. doi: 10.1002/pri.210.

34. Coelho-Junior HJ, Gambassi BB, Irigoyen MC, Goncalves IO, Oliveira PLL, Schwingel PA, et al. Hypertension, Sarcopenia, and Global Cognitive Function in Community-Dwelling Older Women: A Preliminary Study.J Aging Res. 2018;2018:9758040. doi: $10.1155 / 2018 / 9758040$ 
35. Tabony AM, Yoshida T, Sukhanov S, Delafontaine P. Protein phosphatase $2 \mathrm{C}$-alpha knockdown reduces angiotensin II-mediated skeletal muscle wasting via restoration of mitochondrial recycling and function. Skelet Muscle. 2014;4(1):20. doi: 10.1186/2044-5040-420. doi: 10.1186/2044-5040-4-20.

36. Brink M, Wellen J, Delafontaine P. Angiotensin II causes weight loss and decreases circulating insulin-like growth factor I in rats through a pressor-independent mechanism. The Journal of clinical investigation. 1996;97(11):2509-16. doi: 10.1172/JCI118698.

37. Yoshida T, Huq TS, Delafontaine P. Angiotensin type 2 receptor signaling in satellite cells potentiates skeletal muscle regeneration. J Biol Chem. 2014;289(38):26239-48. doi: 10.1074/jbc.M114.585521.

38. Dalla Libera L, Ravara B, Angelini A, Rossini K, Sandri M, Thiene G, et al. Beneficial effects on skeletal muscle of the angiotensin II type 1 receptor blocker irbesartan in experimental heart failure. Circulation. 2001;103(17):2195-200. doi: 10.1161/01.cir.103.17.2195.

39. Brown JD, Smith SM, Strotmeyer ES, Kritchevsky SB, Gill TM, Blair SN, et al. Comparative Effects of Angiotensin-Converting Enzyme Inhibitors and Angiotensin Receptor Blockers on Response to a Physical Activity Intervention in Older Adults: Results From the Lifestyle Interventions and Independence for Elders Study. J Gerontol:Series A 2020;75(5):1010-6. Doi:org/10.1093/gerona/glz120

40. Ishikawa S, Naito S, Iimori S, Takahashi D, Zeniya M, Sato H, et al. Loop diuretics are associated with greater risk of sarcopenia in patients with non-dialysis-dependent chronic kidney disease. PLoS One. 2018;13(2):e0192990. doi: 10.1371/journal.pone.0192990

41. Hanai T, Shiraki M, Miwa T, Watanabe S, Imai K, Suetsugu A, et al. Effect of loop diuretics on skeletal muscle depletion in patients with liver cirrhosis. Hepatol Res. 2019;49(1):82-95. doi: 10.1111/hepr.13244. 